\title{
Examination of Security Features in Nepali Currency of Denomination Rs. 500 and Rs. 1000 Using Video Spectral Comparator-6000
}

\section{R. Giri, P. Bhattarai, S. P. Chimouriya and B. R. Ghimire}

Journal of Nepal Physical Society

Volume 7, Issue 4, December 2021

ISSN: 2392-473X (Print), 2738-9537 (Online)

\section{JNPS}

Editors:

Dr. Binod Adhikari

Dr. Bhawani Joshi

Dr. Manoj Kumar Yadav

Dr. Krishna Rai

Dr. Rajendra Prasad Adhikari

Mr. Kiran Pudasainee

JNPS, 7 (4), 36-42 (2021)

DOI: http://doi.org/10.3126/jnphyssoc.v7i4.42929
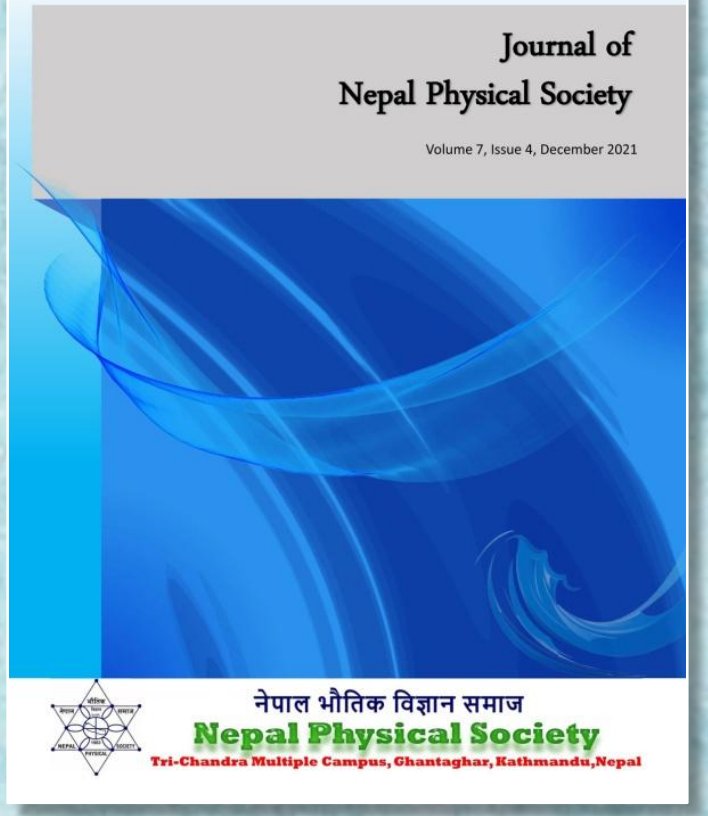
2738-9537 (Online)

Journal of IIme 7 Issue 4, December 2021
ISSN:2392-473X (Print)

Published by:

Nepal Physical Society

P.O. Box: 2934

Tri-Chandra Campus

Kathmandu, Nepal

Email: nps.editor@gmail.com 


\title{
Examination of Security Features in Nepali Currency of Denomination Rs. 500 and Rs. 1000 Using Video Spectral Comparator-6000
}

\author{
R. Giri ${ }^{1}$, P. Bhattarai ${ }^{1}$, S. P. Chimouriya ${ }^{2}$ and B. R. Ghimire ${ }^{3 *}$ \\ ${ }^{1}$ National Forensic Science Laboratory, Khumaltar, Lalitpur, Nepal \\ ${ }^{2}$ Department of Natural Sciences (Physics), Kathmandu University, Kavre, Nepal \\ ${ }^{3}$ Central Department of Physics, Tribhuvan University, Kirtipur, Kathmandu, Nepal \\ *Corresponding Email: balram.ghimire@cdp.tu.edu.np
}

Received: 14th November, 2021; Revised: 13th December, 2021; Accepted: 25th December, 2021

\begin{abstract}
In this work, we have studied security features of Nepali currencies of denomination Rs. 500 and Rs. 1000 of recent two series with the help of Video Spectral Comparator-6000. During examination, mostly ultraviolet, normal, transmitted and oblique light are used. We found nine different security features like fluorescence, water mark, micro text, security thread, intaglio print, see through registor, emboss, optically variable ink and latent image in this work. One feature, latent image is found to be completely removed in new series of both Rs. 500 and Rs. 1000 whereas new important security feature optically variable ink is introduced in new series of Rs. 500. Besides these two features, some are unchanged while some are modified.
\end{abstract}

Keywords: Paper currency, Security features, Counterfeit, Video Spectral Comparator, Denomination.

\section{INTRODUCTION}

Nepal Rastra Bank act, 2002 defines currency as bank notes in circulation in the form of cash and this expression also includes coins [1]. Currency including coins and paper notes is the form of money which is used as a medium of exchange of goods and services. Paper currency is made from cotton and linen [2]. It needs about 4000 folds to tear paper currency. Currency plays vital role in our daily economic activities. Hence, having basic understanding of various security features of paper currency by individual to concerned level authorities is a must. Currency is the basis for trade. Security features of currency are those unique features present in genuine notes which differentiates genuine notes from counterfeit notes. Security printing also plays an important role in developing security features in currency to prevent forgery, tampering and counterfeiting [3]. Counterfeit notes refer to fake notes that are not produced by concerned legal authorities. Nepali paper currencies are fortified with various securities such as water mark, security thread, see through register, micro text, fluorescence etc.
In recent years, many researchers are devoted to study the security features of bank notes of various countries. A. Anjali et al. [4] studied securities features of genuine, scanned and photocopied Indian currency note of the denomination 2000. N. K. Kanwal et al. [5] studied spectral analysis of various security features in Indian currency note of highest denomination using Video Spectral Comparator (VSC)-40. They reveal security features like optical security fibers, fluorescence, water mark, micro text, security thread, intaglio print, see through registor, optically variable ink and latent image in denomination Rs. 1000 first introduced by Reserve Bank of India in 1954, demonetized in January and reintroduced in 2000. M. Sahu et al. [6] studied new identifying security features in Indian currency of denomination of Rs. 2000 presented by Reserve Bank of India in November 2016. M. Mann et al. [2] carried out a comparative study on security features of banknotes of various countries including India, United States of America, Australia, United Kingdom, Euro currency and China. R. Ghos et al. [7] studied 
diverse recognition techniques for Indian currency note. S. K. Pathak et al. [8] carried out the work on spectral analysis on new Indian currency of denomination Rs. 500 using VSC-5000. However, the study of security features of Nepali paper currency is still lacking. In this work, we have tried to reveal security features of Nepali paper currency.

\section{MATERIALS AND METHOD}

This work is based on the examination of various security features in specimen copy of Nepali paper currency issued by Nepal Rastra Bank. For this work, Nepali paper currency of domination Rs. 500 (2012 series and 2016 series) and Rs. 1000 (2016 series and 2019 series) are chosen whose security features are examined by using VSC-6000. We choose these series because currency of these series are circulating in our market now days. We have studied various security features and compared obtained security features in previous and new series of currency. Security features present on paper currency are studied using different light sources, different magnification ranges, spot light and various filters.

Video Spectral Comparator works on the principle of interaction of light of different wavelength with matter. Electromagnetic waves are categorized according to their frequency ' $f$ '. Visible light makes just a small part of the full electromagnetic spectrum. Electromagnetic waves with shorter wavelength and higher frequencies include ultraviolet light, X-rays and gamma rays. Electromagnetic waves with longer wavelength and lower frequencies include infrared light, microwaves and radio waves [9]. Light interacts with matter through many phenomenon like reflection, refraction, diffraction, absorption, emission, scattering, fluorescence, phosphorescence etc. Florescence is photon emission processes which occur during molecular relaxation from electronic excited states. Florescence is short-lived with luminescence ending almost immediately. It takes place from singlet excited states. Phosphorescence takes place from triplet excited states. It involves change in electron spin and may endure for several seconds. Fluorescence gives an immediate flash whereas phosphorescence is a lower 'glow in the dark' appearance [10].

The lifetime of fluorophore in the absence of nonradiative processes is called the intrinsic or natural life time and is given by [11]

$\tau_{\mathrm{n}}=1 / \Gamma$

where, ' $\tau_{n}$ ' is natural life time and ' $\Gamma$ ' is emissive rate of fluorophore.
Fluorescence intensity $(\mathrm{F})$ is directly propertional to the substances which is given as [10]

$\mathrm{F}=\mathrm{Q} \cdot \mathrm{I}_{\mathrm{a}} \cdot \mathrm{a} \cdot \mathrm{c} \cdot \mathrm{t}$

where, 'Q' is constant for particular substance, ' $\mathrm{I}_{\mathrm{a}}$ ' is constant for an instrument, ' $a$ ' is molecular extinction coefficient, ' $t$ ' is path length and ' $c$ ' is concentration of substance.

\subsection{Video Spectral Comparator-6000}

VSC is very useful tool in document examination which allows an examiner to analyze ink [12], reveal alteration in document [13-15], visualize hidden security features in currency [2-8], passport [16,17] etc., determine chronological of crossing strokes $[18,19]$, enhance handwriting on charred documents [20] etc. that uses different light sources for examination of document. At first power of VSC is switch on and appropriate setting is done before working. Paper currency is placed on the document platen under the canopy in the chamber of VSC, which contains the video camera, sources of reflected light and optical filters and a video image is displayed on monitor. The position of currency is adjusted by viewing on the monitor. After placing the currency note, various illumination options in the range of UV (200-400nm), Visible (400-700nm), IR (700$1000 \mathrm{~nm}$ ), illumination geometry, different optical filters and different magnifications are selected to get the required results. Once the required result is obtained, the image is saved.

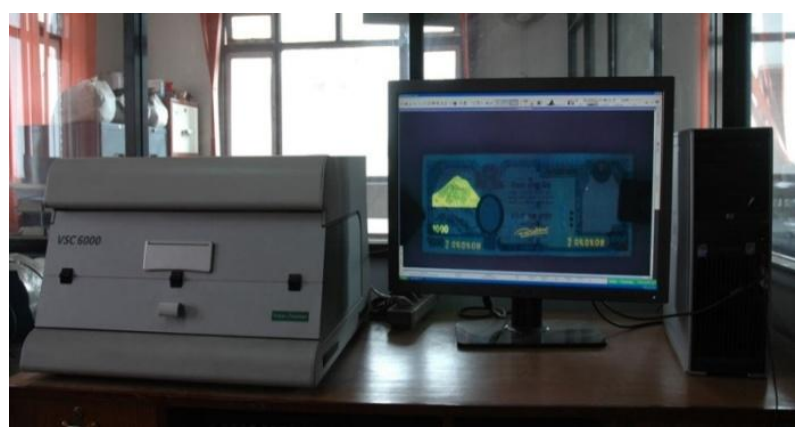

Fig. 1: Video Spectral Comparator-6000

\section{RESULTS AND DISCUSSION}

Many scientific methodologies can be used for examination of security features of paper currency. Following security features are obtained on Nepali paper currency of Rs. 500 and Rs. 1000 using VSC-6000.

\subsection{Fluorescence}

Fluorescence property obtained in paper currency of Rs. 1000 and Rs. 500 is shown in fig 2 and fig 3 respectively. For Rs 1000 note, optimum fluorescence effect is observed in UV light of 
wavelength $254 \mathrm{~nm}$ whilst same effect is observed in $365 \mathrm{~nm}$ UV light for Rs 500 note. In the obverse side of Rs. 1000, fluorescence in signature of governor, bank note number, figure of Mt. Everest and 1000 digit are seen where as in reverse side of Rs 1000, such effect is seen at some lower parts of currency. The intensity of fluorescence at figure of Mt. Everest and 1000 digit is found higher as compared to other fluorescence of other parts in denomination of 1000 (same results are obtained for Rs 500 note as well). Both series 2016 and 2019 of Rs 1000 note are seen to exhibit such effect under UV light. Similarly in obverse part of Rs. 500, such effect can be seen in signature of governor, bank note number, figure of Mt. Everest and 500 digit. However, no fluorescence effect is observed on reverse side of Rs 500 note. No changes are observed in fluorescence among 2012 and 2019 series of Rs 500 denominations. Hence, such fluorescence property is observed as many parts of the banknotes are printed with fluorescent ink.
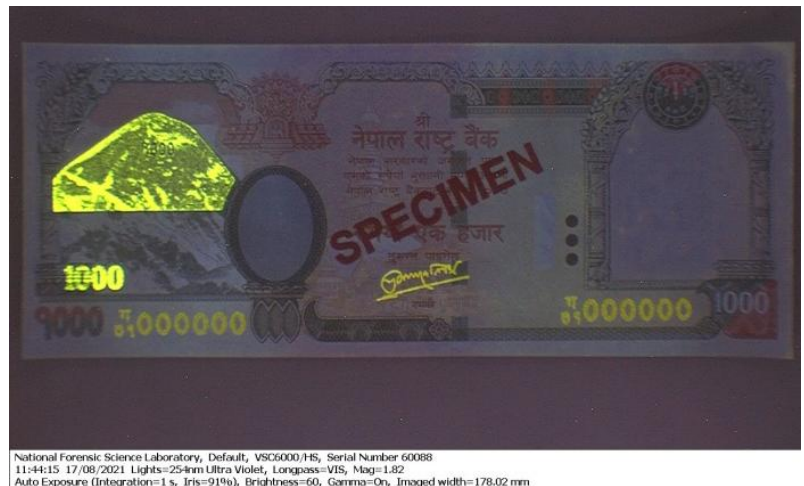

Fig. 2: Fluorescence on obverse side of Rs.1000 of 2016 series as viewed under UV light of wavelength $254 \mathrm{~nm}$

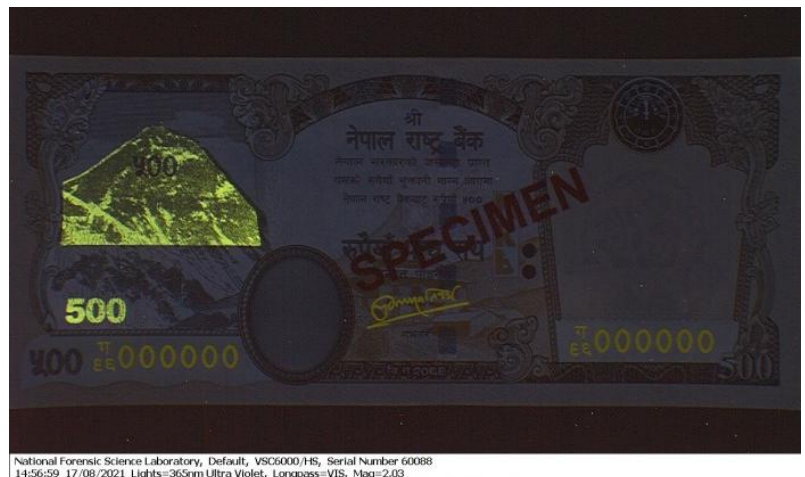

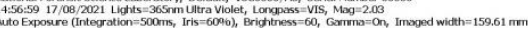

Fig. 3: Fluorescence on obverse side of Rs.500 of 2012 series as viewed under UV light of wavelength $365 \mathrm{~nm}$

\subsection{Water Mark}

Watermark present in Nepali paper currency of Rs. 1000 and Rs. 500 is shown in fig 4. In both, figure of
'Laligurash' as watermark on the right side is clearly observed when viewed with transmitted light.

Watermark is a design which is produced in currency by varying distribution of fibers in the particular space of currency [4]. It looks like three dimensional figures. It can be observed by holding note against light source or via transmitted light. Generally, it is hard to observe watermark in normal light. No changes in water mark are observed in both previous and recent serious of Rs. 500 as well as Rs. 1000 denominations.

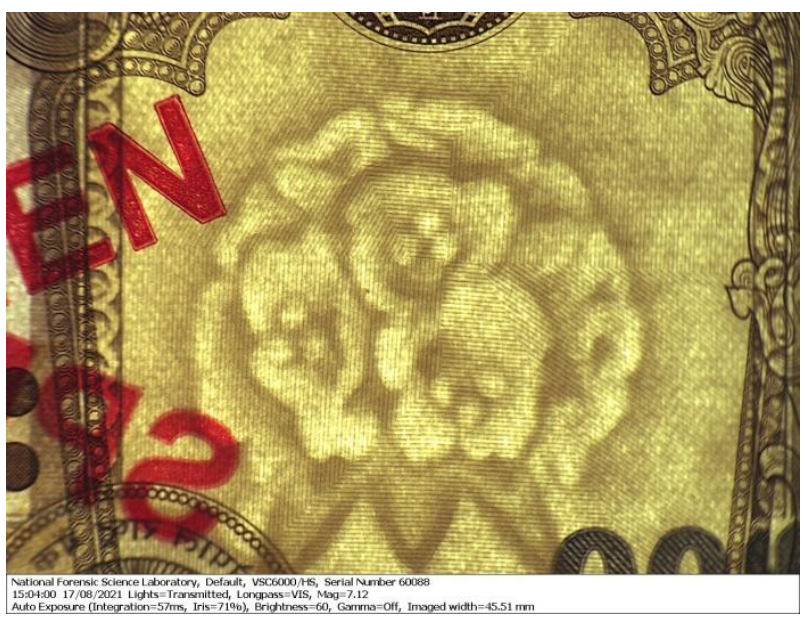

Fig. 4: Water mark observed in Rs. 500 of 2012 series under transmitted light

\subsection{Micro Text}

Micro lettering or micro text refers to very minute inscription on currency which can be well observed under magnifying lens. In case of Nepali currency 'NEPAL RASTRA BANK' is written as micro text in both Rs. 1000 and Rs. 500 as shown in fig 5 which is present in different parts of currency.

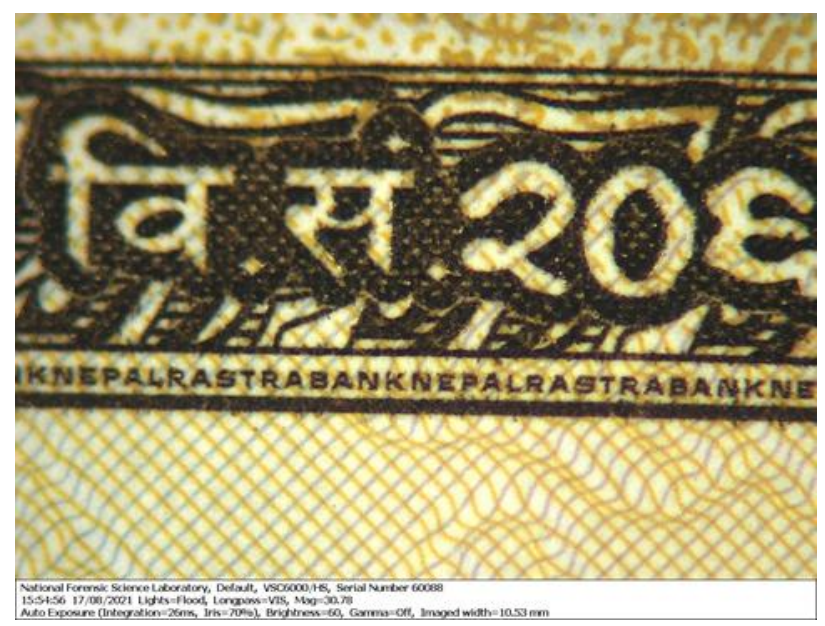

Fig. 5: Micro text found in Rs. 500 of 2016 series observed under high magnification 
No changes to this security features are made between older and new series of notes. Micro text is one of an anti-counterfeiting measure present in paper currency because methods of photocopy, image scanning etc. produce dotted or solid lines. Under high magnification only, it is observable whereas without magnification, letters or text appear as a line. Nepalese currency shows high quality of micro text.

\subsection{Security Thread}

It is thread like structure found in bank note. In Rs. 500 and Rs. 1000, security thread is embedded within currency which looks like alternate band of thread when viewed from one side of note but when observed against light source or transmitted light, it forms a complete thread. Denomination of Rs. 500 and Rs. 1000, when held against the light, displays the security thread as one continuous thread. In security thread, 'NRB' as small letter can be seen in Rs. 500 of 2012 series. In new series of Rs. 500 i.e. 2016 series, only digit 5 is written. Significant modification on security thread of denomination Rs. 1000 between two series can be observed. In 2016 series 'NRB' is written in small letter whereas in 2019 series, security thread is made light sensitive containing micro text 'NRB' and '1000' as shown in fig 6.

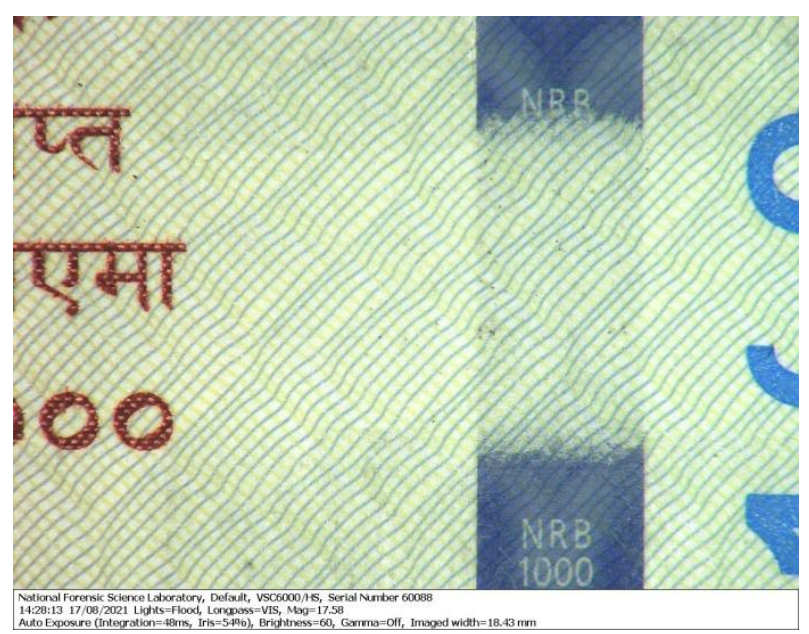

Fig 6: Security thread on Rs. 1000 of 2019 series under normal light

\subsection{Intaglio Printing}

Raised prints of currency in inscription is known as intaglio printing which can be felt by touching which also acts as blind recognition feature . Oblique light reveals such feature. This security feature is found in Nepali currency of Rs. 1000 which is shown in fig 7 . No changes are observed in intaglio printing property among 2012 series and 2016 series of Rs. 500 denomination as well as 2016 series and 2019 series of Rs. 1000 denominations. Such effect is found in "description about bank note written in Nepali language" at middle part of observe side and "amount of note written in digit at bottom of left part" of observe side in both denominations.

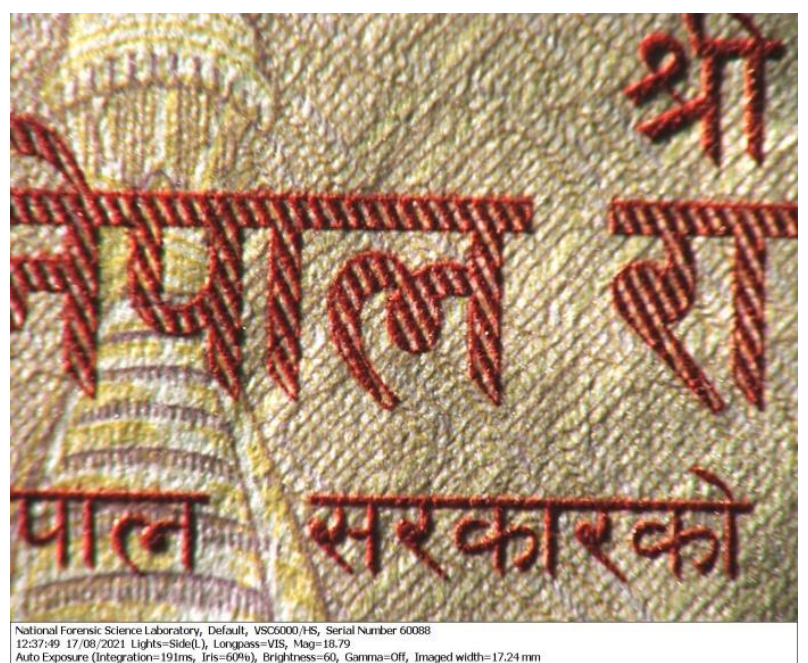

Fig. 7: Intaglio printing on Rs. 1000 of 2016 series viewed in oblique light

\subsection{See through Register}

While viewing from obverse and reverse side of Rs. 500 only half portion of 'NRB' is seen which forms complete 'NRB' which when viewed through transmitted light and against light. This security property is the same in both 2012 series and 2016 series of Rs. 500. Exactly the same feature is found in Rs. 1000 of 2016 series. New type of see through register is introduced in Rs. 1000 of 2019 series, in which from obverse or reverse side, only half portion of digit ' 1000 ' is seen while viewed through transmitted light and against light.

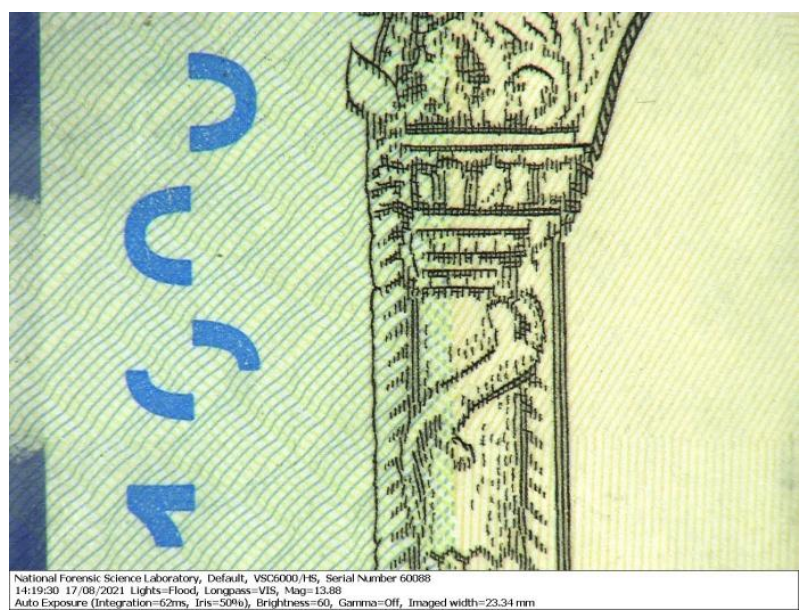

Fig 8: See through register on Rs. 1000 of 2019 series when viewed under normal 


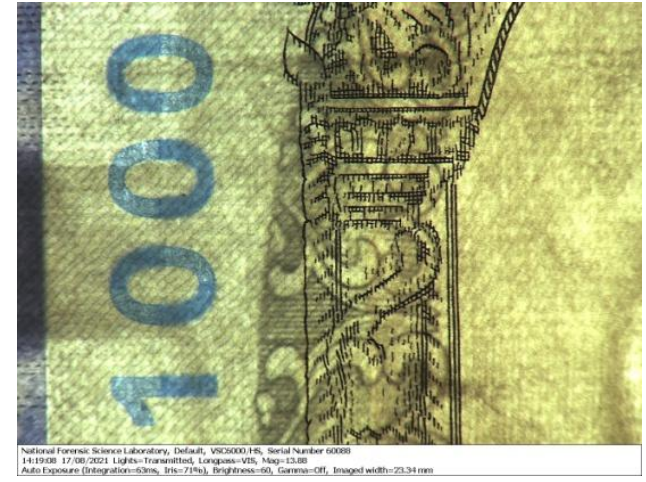

Fig 9: See through register on Rs. 1000 of 2019 series when viewed under transmitted light

\subsection{Emboss}

Embossing is the process of creating raised images using specific tool. It can be felt by touching also. In Nepali currency of high denominations, image of god is embossed which can be observed when viewed using oblique light. In case of Rs. 1000 of both series 2016 and 2019, there is no change in emboss feature. Similarly in Rs. 500 of series 2012, image of god is embossed as shown in fig 10 and fig 11. But embossing security feature is replaced with new feature called optically variable ink in denomination of Rs. 500 of series 2016.

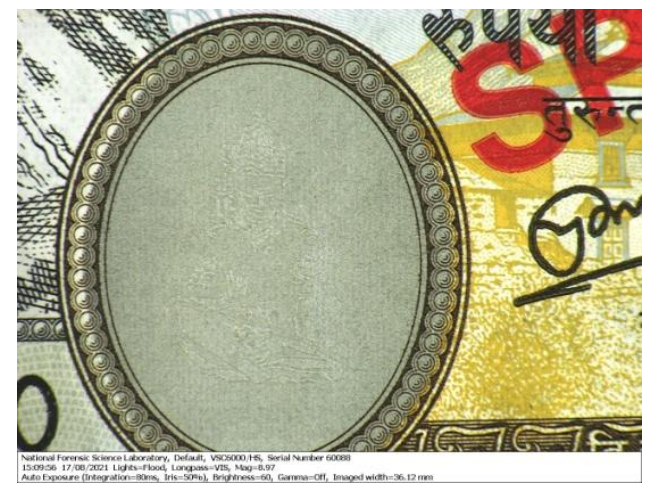

Fig 10: Emboss on Rs. 500 of 2012 series under normal light.

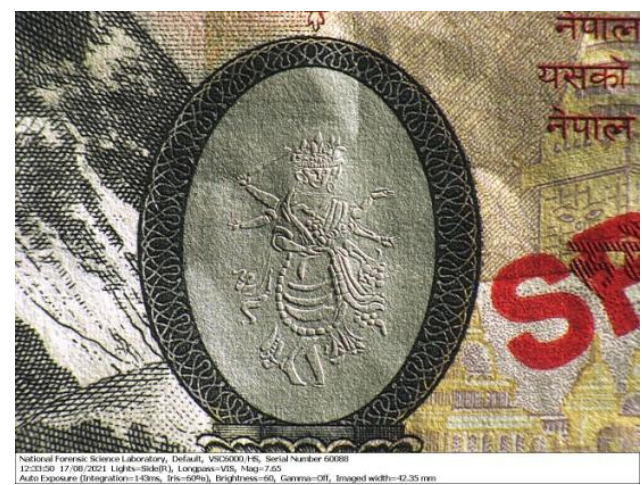

Fig 11: Emboss on Rs. 500 of 2012 series viewed under oblique light

\subsection{Optically Variable Ink}

This is newly introduced security feature in Rs. 500 of series 2016 which is totally absent in paper currency of denomination Rs. 1000 in both 2016 series and 2019 series. The color in image of god is changed when viewed from various angles as shown in fig 12 and fig 13. The colour of the goddess appears golden when the note is held in horizontal plane but changes to dark brown when the note is held at an angle. This security feature is regarded as one of the most important feature because it can be checked in our daily life too by viewing from various angles.

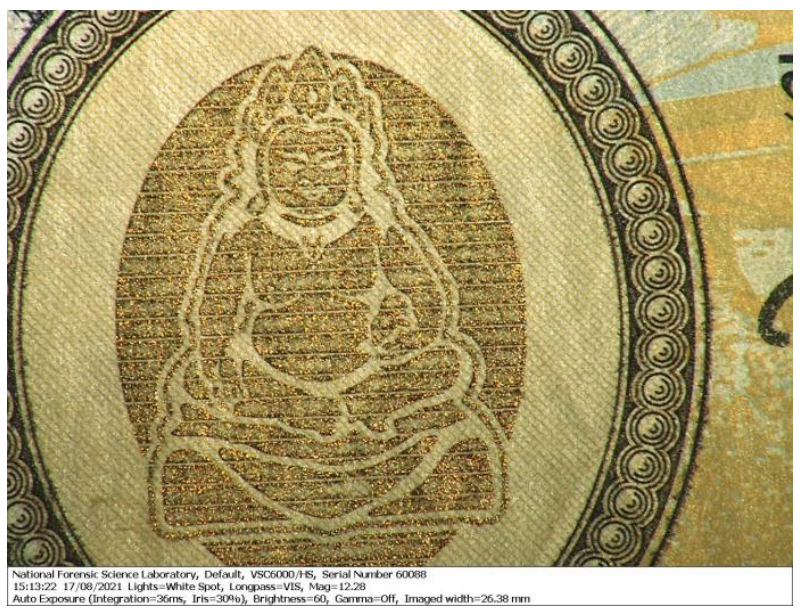

Fig 12: Optically variable ink on Rs. 500 of 2016 series when viewed from normal light

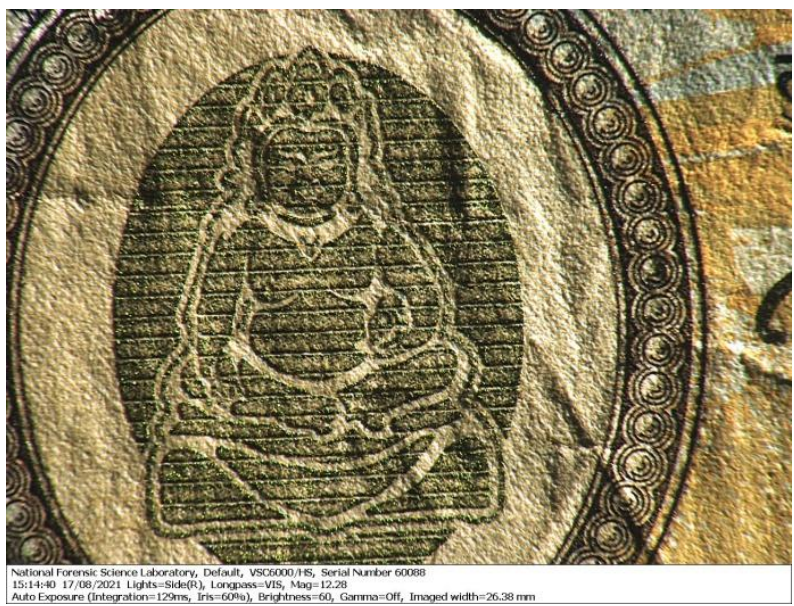

Fig. 13: Optically variable ink on Rs. 500 of 2016 series when viewed from oblique light

\subsection{Latent Image}

Latent image refers to hidden image. In Nepalese paper currency of Rs. 500 of series 2012 and Rs. 1000 of series 2016, latent image as security feature is present. Digit ' 500 ' is written in denomination of 
Rs. 500 and digit ' 1000 ' is written in denomination of Rs. 1000 as latent image which cannot be observed not only in normal view but also under high magnification. By the combined application of high magnification and oblique light only, this feature is observed. In case of denomination of Rs. 500 of series 2012, this feature is present just above the emboss whereas in denomination of Rs. 1000 of series 2016, such feature is observed above the see through register. This feature is completely absent in the new series of Rs. 500 (2016 series) and Rs. 1000 (2019 series) denominations.

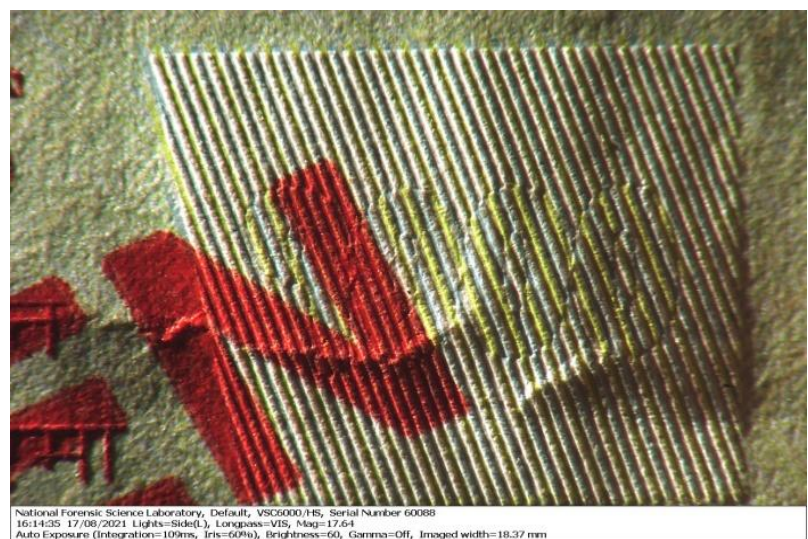

Fig. 14: Latent image on 1000 of 2016 series viewed under high magnification and oblique light

\section{CONCLUSION}

In this work, nine different type of security features (fluorescence, water mark, micro text, security thread, intaglio print, see through registor, emboss, optically variable ink and latent image) present in Nepali paper currency of denomination Rs. 500 (2012 series and 2016 series) and Rs. 1000 (2016 series and 2019 series) are observed by using VSC6000. Among them, eight features are found to be common in both denominations of Rs. 500 and Rs. 1000. Optically variable ink feature is introduced in denomination of Rs. 500 in new series (2016 series) in the place of emboss. Very important feature, latent image is completely absent in new series of both denominations. We obtain some changes in security thread and see through resistor in new series (2019 series) of Rs. 1000. In this change, security thread is made light sensitive containing micro text 'NRB' and digit ' 1000 ' while see through registor is completely changed into digit ' 1000 ' in place of 'NRB'. Similarly, in new series of Rs. 500 (2016 series), small change in micro text of security thread is observed where micro text 'NRB' is replaced by digit ' 5 '.

\section{ACKNOWLEDGEMENT}

Authors R. Giri and P. Bhattarai would like to acknowledge National Youth Council, Sanothimi, Bhaktapur for financial support to this work.

\section{REFERENCES}

[1] Nepal Rastra Bank Act, 2002.

[2] Mann, M.; Shukla, S. K. and Gupta, S. A comparative study on security features of banknotes of various countries. International Journal of multidisciplinary Research and Development, 2(6): 83-91 (2015).

[3] Pinki Ms. Study of new security features of Indian Rupee note. International Journal of Engineering Sciences \& Research Technology, 6: 783-786 (2017).

[4] Anjali, A.; Abhisek, A.; Uttam, S.; and Priyanka, V. Comparison of Various Security Features of Genuine, Scanned and Photocopied Indian Currency Note of the Denomination 2000. Journal of Forensic Science \& Criminology, 5(3): 1-12 (2017).

[5] Kanwal, N. K.; Jat, D. and Malhotra, M. Spectral analysis of various security features in the Indian currency note of highest denomination using Video Spectral Comparator-40. International Journal of Innovative Science, Engineering \& Technology, 1(11): 823-841 (2015).

[6] Sahu, M. and Sinha, M. New Identifying Security Features of Indian Currency. International Journal of Advanced Research, 5: 2049-2053 (2017).

[7] Ghos, R. and Khare, R. A Study on Diverse Recognition Techniques for Indian Currency Note. International Journal of Engineering Sciences \& Research Technology, 2: 1443-1447 (2013).

[8] Pathak, S. K. and Paul, A. Spectral Analysis of New Indian Currency of Denomination 500 Using VSC-5000. International Journal of Innovative Science Engineering \& Technology, 6: 120-135 (2019).

[9] White, H. E. Introduction to Atomic Spectra. McGRAW-HILL BOOK COMPANY, (1934).

[10] Bose, A.; Thomas, I.; Kavitha, G. and Abram, E. Fluorescence spectroscopy and its application : A Review. International Journal of Advances in Pharmaceutical Analysis, 8: 1-8 (2018).

[11] Lakowicz, J. R. Principles of Fluorescence Spectroscopy, Springer Science+Business Media, LLC, Second Edition (1999).

[12] Manal, A. E. and Abd, E. Different types of ink having certain medicolegal importance: Deciphering the faded and physically erased handwriting. Egyptian Journal of Forensic Sciences, 4: 39-44 (2014). 
[13] Khairkar, S. R.; Gaikawad, S. V.; Kokare R. N. and Daundkar, B. B. Forensic Discrimination Potential of Video Spectral Comparator and Micro Spectrometer in Analyzing Question Document and Fraud Cases in India. Journal of Forensic Research, 7(3): 1-4 (2016).

[14] Bamburde H. K. and Goutam, M. P. Questioned Documents Analysis for Decipherment of Obliterated Writing. International Journal of Science and Research, 9(1): (2020).

[15] Pandey, R. K.; Sankhla M. S. and Kumar, R. Forensic Investigation of Suspected Document for Alteration, Erasures \& Obliteration. Galore International Journal of Applied Science and Humanities, 2(1): (2018).

[16] Gupta, R. R. and Ravi, N. Passport Forgery and Forensic Examination of Indian Passport. Journal of Forensic Sciences and Criminal Investigation, 5(1): (2017).
[17] Gupta, S.; Gupta, K. and Singla, A. Advancement in Indian Passport-A Forensic Perspective. International Journal of Engineering and Technology, 3(11): 585-591 (2016).

[18] Vaid, B. A.; Rana R. S. and Dhawan, C. Determination of Sequence of Strokes Through Reflection Spectra. Problems of Forensic Science, Vol-LXXXVII: (2011).

[19] Kaur, R.; Saini K. and Sood, N. C. Application of Video Spectral Comparator (absorption spectra) for establishing chronological order of intersecting printed strokes and writing pen strokes. Science and Justice, 53: 212-219 (2013) .

[20] Moorthy, T. N. and Narayanan, K. Enhancement of Handwriting on Selected Charred Documents using Video Spectral Comparator (VSC), Arab Journal of Forensic Sciences \& Forensic Medicine, (2016). 